\title{
Lo que hicimos bien*: pautas para una nueva mirada a nuestra narrativa republicana ad portas del bicentenario
}

\author{
WHAT WE DID WELL: GUIDELINES FOR A NEW LOOK \\ AT OUR NARRATIVE ON THE EVE OF THE BICENTENNIAL
}

Daniel Parodi Revoredo

Universidad de Lima

\section{RESUMEN}

Este ensayo plantea la posibilidad de convocar el proyecto historiográfico Lo que hicimos bien. Parte de la premisa de que tanto la historiografía tradicional, la historia oficial y las revisiones históricas desde las escuelas marxistas y dependentista han contribuido a la construcción de un relato hipercrítico de la historia republicana del Perú que excluye cualquier atisbo de éxito de la narración. La presente reflexión busca, desde premisas posmodernas, ampliar la mirada y sumarle a la narrativa histórica oficial historias cotidianas de éxito, de mujeres y colectivos hasta hoy excluidos del relato para así recrear el pasado desde múltiples miradas y, de acuerdo con las metas fundacionales de la república, sumarle optimismo a nuestra percepción del pasado. De esta manera, es posible secundar y potenciar la promesa republicana de libertad, inclusión e igualdad.

PALABRAS CLAVE: bicentenario, historia oficial, posmodernidad, historia, narratividad
ABSTRACT

This essay raises the possibility of convening the historiographical project What we did well. Part of the premise that both the traditional historiography, the official history, and the historical revisions from the Marxist and dependentista schools, have contributed to the construction of a hypercritical account of the republican history of Peru that excludes any hint of success from the narrative. This reflection seeks, from postmodern premises, to broaden the gaze and add to the official historical narrative, daily success stories of women and groups until today excluded from the story in order to recreate the past from multiple perspectives and, in accordance with the founding goals of the republic, add optimism to our perception of the past in order to support the republican promise of freedom, inclusion and equality.

KEYWORDS: bicentennial, official history, postmodernity, history, narrativity

\footnotetext{
* El presente ensayo es la versión académica de la conferencia magistral del mismo nombre pronunciada por su autor en el Congreso de la República del Perú el viernes 22 de junio del 2018.
} 
Ad portas del bicentenario de nuestra república, muchos pensamos que conmemoramos solo aquello que sucedió hace 200 años, pero no es así. En realidad, lo que conmemoramos es todo lo que hicimos, y dejamos de hacer, desde entonces hasta ahora. Y es por eso que, junto a los festejos por la proclamación de la independencia en Lima en 1821 y por las batallas de Junín y Ayacucho en 1824, nos toca también reflexionar sobre lo que hemos sido; y preguntarnos en qué ha devenido esa promesa republicana, peruana, de la que hace ya tiempo nos habló Jorge Basadre (1958).

Cuando iniciaba mi labor docente desempeñándome en colegios de educación secundaria, un estudiante de cuarto año, extranjero, casi se burló de nuestra historia; de hecho, consideraba mejor la de su país y a la nuestra patética. Ese joven me dejó pensando y colegí que tenía razón, pues enseñé una independencia cuyos próceres principales no eran peruanos; una república inicial llena de caudillos militares que, apenas al inicio, hicieron trizas aquella promesa republicana a punta de revoluciones, guerras civiles y golpes de Estado; una república guanera en la que nos dedicamos a robar y en la que robamos tanto, pero tanto que llegamos en bancarrota a la guerra del Pacífico, que resultó ser entonces algo así como la expiación de los pecados anteriores: el trauma nacional que no podía sino serlo, como castigo por todo lo anterior (Parodi, 2019; Sagredo, 2004).

Es que la guerra del Pacífico nos la merecimos porque lo que hicimos antes, lo hicimos muy, pero muy mal; y aunque el discurso denuncia también la agresión militar de la que fuimos objeto, la autocrítica al propio proceso, la autocondena, la adjudicación de la propia culpa, es una muy pesada carga que cada bimestre o cada semestre de cada año lectivo de nuestros colegios y universidades colocamos sobre las espaldas de generaciones y generaciones de peruanos. ¿Pretendemos así ser una república de ciudadanos que aman a su patria?

El discurso, en realidad, adopta ribetes tan dramáticos que alguna vez se me dio por nombrar a la narrativa tradicional sobre nuestro siglo XIX independiente como una historia autoflagelante. $Y$ toda vez que la guerra la perdimos por todo lo que hicimos o dejamos de hacer antes de que ella ocurriese, entonces, resulta que cualquier discurso, cualquier análisis, cualquier manual escolar que refiriese el período anterior a aquella, para resultar verosímil, no podía sino criticar duramente nuestros primeros cincuenta años de vida libre. Cualquier atisbo de progreso o cualquier cosa bien hecha debía por defecto ser descartada.

Lo que pasó, y es comprensible, es que nuestra primera generación de historiadores escribió desde el dolor de la derrota militar, desde el quebranto de la tierra invadida, desde la vergüenza del honor mancillado, de ese sentido del honor tan vigente en el siglo XIX, y será por eso que se nos ha quedado como un membrete en la frente a todos los peruanos la vieja frase de González Prada, "los jóvenes a la obra y los viejos a la tumba". 
Aunque el maestro anarquista nos dicta otra sentencia aún más severa, leída precisamente por un estudiante escolar en el Teatro Politeama: "Los viejos deben temblar ante los niños, porque la jeneración que se levanta es siempre acusadora i juez de la jeneración que desciende" (González Prada, 1888).

¿Es mi intención criticar al maestro González Prada? ¡Claro que no! Al contrario, sus palabras me sirven para desarrollar dos ideas. La primera es que las palabras de Prada nos permiten comprender la atmósfera del período de posguerra y colegir cuánto pudo influir en la manera como nos redactaron y nos representaron en la historia precedente. La segunda, que el enfoque positivista es absolutamente explícito cuando señala Prada que la nueva generación es la jueza de sus predecesoras.

Y qué mejor juez del pasado que el historiador, convencido de que la prueba documental, tan igual que en el derecho, lo provee de la autoridad para sentenciar lo que hicimos bien y lo que hicimos mal en el pasado. Es con ese temperamento que se escribió la historia del siglo XIX, y la pregunta que dejo en el aire es hasta qué punto ese mismo temperamento invade, apenas a meses de conmemorar nuestro bicentenario, a las aulas escolares y universitarias de nuestro país. Por eso he dicho tantas veces que hay que dejar de pensar la historia del Perú independiente, desde su fundación política hasta 1883, como un relato estructurado de tal forma que su conclusión solo puede ser la guerra del Pacífico, a la manera de una tragedia griega, nada menos (Bloch, 1952; White, 1992).

En el siglo xx no voy a adentrarme demasiado en estas líneas, porque considero que la idea central de esta exposición, al menos en cuanto a la crítica de nuestra narrativa oficial acerca de la historia de nuestra república, ha sido ya planteada; pero sí quisiera dejar sentado que ha llegado el momento de disputarle a la historiografía del siglo xx otra carga también muy pesada, como lo es el enfoque de la lucha de clases.

Desde ese punto de vista, no solo se nos ha dividido a los peruanos entre ricos y pobres, sino que se presenta inexorablemente a los ricos como los malos del cuento. Yo no puedo negar que el gamonalismo andino prolongó el régimen colonial hasta 1969, cuando la ley de reforma agraria finalmente liquidó el latifundio, ni que el Perú republicano, en cuanto continuación del colonial, ha sido por definición injusto y básicamente lo sigue siendo. Por el contrario, me sumo a la denuncia de un régimen terrateniente que mantuvo a nuestro campesino en una inaceptable situación de servidumbre y postración hasta bien entrado el siglo xx, y de una clase política que, como señalase Yépez del Castillo (1972) hace casi cincuenta años, solo se animó a constituirse en tal cuando José Balta y Nicolás de Piérola, conspicuos representantes del caudillismo civil o militar entonces vigente, afectaron sus intereses al firmar con la Casa Dreyfus un contrato que los despojó del negocio guanero. 
Pero quizá porque soy historiador es que prefiero colocar a cada actor histórico en su contexto, y es por eso que no puedo andar por la vida, y por la historia, adjudicando el rol de malos y buenos así tan fácilmente. Al contrario, en el aula de clase, cuando trato temas tan sensibles, pongo como ejemplo la bella cinta El último emperador (1987), de Bernardo Bertolucci, que nos cuenta la historia de Puyi, el último emperador de China, quien, de niño, al pasear por los jardines de la Ciudad Prohibida, observaba inocentemente cómo cientos de sirvientes se arrodillaban ante él.

La cinta nos muestra, en uno de sus pasajes más conmovedores, la crisis existencial del joven emperador cuando comprendió que solo imperaba dentro de las paredes de su palacio, debido al triunfo de la revolución nacionalista de Chiang Kai-shek en 1912. ¿Era culpable Puyi de su propia crisis existencial? ¿Era responsable de pretenderse casi un Dios en un mundo que solo supo ver inclinarse ante él?

Creo que, a estas alturas de mi exposición, va quedando claro que lo que les estoy trayendo no es una disertación acerca de la gesta emancipadora, o de algún período específico de nuestra historia republicana. Lo que les traigo es un proyecto que se llama Lo que hicimos bien, y estuve reflexionando sobre algunas observaciones que se le plantearán. ¿Cómo es eso de una historia que se ocupe solo de lo bueno? Esa será de seguro la principal observación.

Quisiera ensayar una primera respuesta a través de otra pregunta: ¿y por qué una historia que solo se ocupe de lo malo? Porque vaya que existen. Hace algunos años se publicó la Historia de la corrupción en el Perú (Quiroz, 2013), investigación por cuyo rigor académico expreso mi absoluto respeto, tanto como por su autor que desgraciadamente ya no está entre nosotros; y ni qué hablar de la historia de la escuela, la de los manuales escolares, que cuando trata el siglo XIX reproduce una y otra vez la frustración que con justicia invadió a González Prada en el Politeama. Pero resulta que entre aquellos tiempos y los nuestros median 120 años y aún no hemos cumplido la promesa republicana, y ni siquiera contamos con un discurso aglutinador que nos explique más a nosotros mismos (Quiroz, 2013). Lo más preocupante es que ni historiadores ni científicos sociales nos hemos tomado el trabajo de buscarlo, ni mucho menos de intentar producirlo, ni siquiera en el contexto del bicentenario y a pesar de que, desde que sonaran las campanas de la mitad del siglo pasado, este país se ha transformado socioculturalmente como no lo ha hecho ninguno, tal vez Inglaterra en su lapso 1750-1850, o China, claro, los últimos 40 años, y paro de contar.

Podrá decirse que esta propuesta de Lo que hicimos bien es maniqueísmo puro y duro, que no se puede ni borrar todo lo malo que nos sucedió, ni escribir la historia de manera tan arbitraria. Tengo algunas cosas que decir al respecto: la primera es que toda historia es arbitraria, y, pido perdón si decepciono a alguno, pero la historia verdadera de lo que realmente aconteció no existe. 
Existen explicaciones, interpretaciones del pasado, pero desde el momento en que el historiador selecciona y prioriza un dato, un documento, un acontecimiento sobre otro, ya está siendo arbitrario, y no puede sino serlo. La historia la conocemos siempre a través de una mediación, y la mediación, a su vez, remite inexorablemente al objetivo que persigue el investigador, a su tiempo, su formación e ideología (Ricoeur, 1999).

Quiero detenerme, si me permiten, en un elemento adicional. Ya desde hace tres décadas, cuando cayó el muro de Berlín, advino la globalización y terminó de advenir la posmodernidad. Y entonces la historia, esa que era una sola y se escribía en singular, estalló en mil pedazos. Es por eso que hoy la dimensión histórica está colmada de miles y miles de relatos, de mujeres, de obreros, de comunidades, de diferentes colectivos que pugnan para que los demás escuchen lo que tienen para contarles (Beltrán, 2001).

Hoy la historia, y en realidad hace tiempo ya, se ocupa de lo cotidiano, de las mentalidades, de la culinaria, de la moda, de la historia pequeñita, de la familiar, y ese tiene que comenzar a ser nuestro enfoque, porque ese es el enfoque contemporáneo. Y es precisamente por ese enfoque contemporáneo que queremos no la historia, sino una historia o, mejor dicho, un espacio de historia donde los peruanos y los ciudadanos del mundo podamos encontrar con facilidad los episodios positivos de nuestro devenir independiente.

¿Cuál es, pues, el objetivo de Lo que hicimos bien? Pues que el maestro universitario o de educación secundaria, el padre o la madre de familia interesados, el mismo estudiante, el connacional adulto mayor, adulto o joven, que quiera conocer las cosas buenas que hicimos en estos 200 años de vida independiente, sepa adónde ir a buscar, y no solo al libro impreso en la librería o biblioteca, sino, lo más importante, al ciberespacio, donde la encontrará perfectamente catalogada, con hipervínculos para que escoja libremente aquel relato que le llame más la atención.

¿Que queremos arbitrariamente ocultar lo malo y reemplazarlo por lo bueno? Insisto: no y mil veces no. Lo que buscamos, más bien, es que exista un espacio para las cosas buenas en la historia republicana del Perú, por una razón sencilla y que es, en efecto, instrumental: no existe.

Y, bueno, pues, ¿cuáles son esas historias buenas? Lamento decepcionarlos, pero no figura entre mis intenciones convertirme en lo que tanto molestaba a los maestros franceses Marc Bloch (1952) y Lucien Febvre (1982), es decir, en el supremo árbitro del pasado y así señalar: esta historia sí, esta historia no. Ya hemos tenido muchos historiadores, y hasta aficionados, entre ellos muchísimos políticos y abogados, metidos a jueces implacables del pasado, sentenciando quiénes ameritan ser tratados como héroes y quiénes como villanos, ¡basta!

Lo que quiero proponerles es lanzar una gran convocatoria a los historiadores del país para enviarnos sus propuestas; por supuesto que un comité especializado de 
historiadores tendrá finalmente que hacer eso que he definido como arbitrario; es decir, seleccionar, porque seguramente serán muchísimas las propuestas que tendremos que evaluar. Sí tenemos una premisa: que estas historias sean lo más consensuales que se pueda y, al mismo tiempo, lo más republicanas e inclusivas posible, pues se trata, no lo olvidemos, de la conmemoración del bicentenario de una república liberal y democrática. Esa fue nuestra promesa fundacional hace casi 200 años, la de la libertad y la igualdad, la de historias que nos permitan a todos y todas ser felices compartiendo lo que tenemos en común, pero también nuestras diferencias.

\section{PAUTA FINAL}

Una pauta que podría alcanzarles en las líneas finales de esta reflexión es la siguiente: no nos dejemos llevar por el ceci tuera cela; ni la historia, así como tampoco el presente, deben comprenderse como un ajuste de cuentas con el pasado. Qué duda cabe de que la historia oficial ha abusado de estereotipos militares masculinos, pero abrir la cancha de la historia no pasa por derrumbar las estatuas de Simón Bolívar o Francisco Bolognesi, sino por difundir las historias de las mujeres, en el plano individual y el social, y así, de la misma manera, las de las grandes mayorías, y también las de las grandes minorías, secularmente postergadas, cuyas historias de éxito y sus frustraciones no merecen perderse en el olvido.

En los años ochenta, una familia clase mediera, la mía, veraneaba en San Bartolo. Los viernes, al dirigirnos hacia el litoral del sur, atravesábamos el distrito de Villa El Salvador por la carretera Panamericana. El panorama lo conformaban miles de chozas de esteras, todas amarillas. Era el Perú del Desborde popular (1984) de Matos Mar abriéndose paso. Sus viejos vecinos todavía llaman el arenal a Villa El Salvador porque alguna vez lo fue, pero lo cierto es que donde una vez hubo arena hoy se erige una ciudad, y el Perú bicentenario está lleno de ejemplos como este.

Cómo nos sentimos, en cuanto peruanos, ad portas del bicentenario es un tema que depende mucho de cómo narramos nuestro pasado. La denuncia de lo que hicimos mal no puede suprimirse del relato, pero tampoco puede apoderarse del relato. Conociendo lo que hicimos bien nos resultará más sencillo retomar la promesa de los padres fundadores porque podremos recordar las veces que estuvimos en el camino correcto, para así encontrarlo nuevamente de cara hacia un futuro de democracia, desarrollo, inclusión y libertad. 


\section{REFERENCIAS}

Basadre, J. (1958). La promesa de la vida peruana y otros ensayos. Lima: Mejía Baca.

Beltrán, M. Á. (2001). Pensar la historia en ¿tiempos posmodernos? Memoria y Civilización, 4, 19-41.

Bloch, M. (1952). Introducción a la historia. Ciudad de México: Fondo de Cultura Económica.

Febvre, L. (1982). Combates por la historia. Barcelona: Ariel.

González Prada, M. (1888). Discurso en el Politeama. Recuperado de https://www. voltairenet.org/article120667.html

Matos Mar, J. (1984). Desborde popular y crisis del Estado. Lima: Instituto de Estudios Peruanos.

Parodi, D. (2019). Lo que decimos de ellos. La guerra del Pacífico en la historiografía y manuales escolares peruanos. Lima: Universidad de Lima, Fondo Editorial.

Quiroz, A. W. (2013). Historia de la corrupción en el Perú. Lima: Instituto de Estudios Peruanos; Instituto de Defensa Legal.

Ricoeur, P. (1999). Historia y narratividad. Barcelona: Paidós.

Sagredo, R. (2004). Basadre y la guerra del Pacífico: de la historia como expiación a la historia como posibilidad. En S. O'Phelan y M. Ricketts (Comps.), Homenaje a Jorge Basadre. El hombre, su obra y su tiempo. Lima: Instituto Riva-Agüero; Universidad del Pacífico; Instituto Cultural Peruano-Norteamericano.

White, H. (1992). Metahistoria. La imaginación histórica en la Europa del siglo xix. Ciudad de México: Fondo de Cultura Económica.

Yépez del Castillo, E. (1972). Perú 1820-1920. Un siglo de desarrollo capitalista. Lima: Instituto de Estudios Peruanos; Campodónico Editores. 